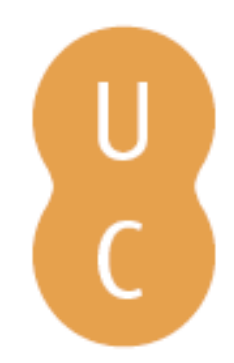

\title{
nommalina
}

\section{Análise ecodinâmica dos municípios costeiros de Barra dos Coqueiros e Pirambu} (SE, Brasil)

\author{
Autor(es): $\quad$ Costa, J. J.; Barbosa, A. M. F.; Souza, R. Melo e \\ Publicado por: Imprensa da Universidade de Coimbra \\ URL \\ persistente: URI:http://hdl.handle.net/10316.2/31424 \\ DOI: $\quad$ DOI:http://dx.doi.org/10.14195/978-989-26-0531-9_7 \\ Accessed : $\quad$ 26-Apr-2023 11:33:56
}

A navegação consulta e descarregamento dos títulos inseridos nas Bibliotecas Digitais UC Digitalis, UC Pombalina e UC Impactum, pressupõem a aceitação plena e sem reservas dos Termos e Condições de Uso destas Bibliotecas Digitais, disponíveis em https://digitalis.uc.pt/pt-pt/termos.

Conforme exposto nos referidos Termos e Condições de Uso, o descarregamento de títulos de acesso restrito requer uma licença válida de autorização devendo o utilizador aceder ao(s) documento(s) a partir de um endereço de IP da instituição detentora da supramencionada licença.

Ao utilizador é apenas permitido o descarregamento para uso pessoal, pelo que o emprego do(s) título(s) descarregado(s) para outro fim, designadamente comercial, carece de autorização do respetivo autor ou editor da obra.

Na medida em que todas as obras da UC Digitalis se encontram protegidas pelo Código do Direito de Autor e Direitos Conexos e demais legislação aplicável, toda a cópia, parcial ou total, deste documento, nos casos em que é legalmente admitida, deverá conter ou fazer-se acompanhar por este aviso.

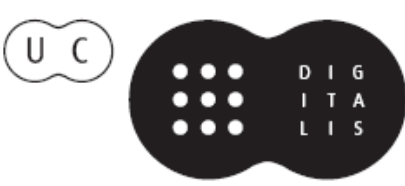





\title{
ANÁLISE ECODINÂMICA DOS MUNICÍPIOS COSTEIROS DE BARRA DOS COQUEIROS E PIRAMBU (SE, BRASIL)
}

\author{
ECODYNAMICS ANALYSIS OF COASTAL MUNICIPALITIES \\ OF BARRA DOS COQUEIROS AND PIRAMBU (SE, BRAZIL)
}

\begin{abstract}
Resumo - As diversas formas de atuação dos elementos que compóem a biosfera causam em cada espaço conseqüências muito diferentes. A dinâmica do meio ambiente é de extrema importância para a conservação e desenvolvimento dos vários recursos ecológicos existentes na superfície terrestre. Desse modo, fazendo um paralelo com a constituição das unidades de paisagem, observa-se constantemente modificaçôes nos elementos componentes destes ecossistemas. Objetivou-se analisar como a dinâmica dos ecótopos contribui para a formação e reestruturação ambiental do litoral norte do estado de Sergipe. Para isso, a metodologia de trabalho utilizada baseou-se nos princípios da Ecodinâmica de TRICART (1977), avaliando os processos morfodinâmicos encontrado na área, os quais caracterizam os meios estáveis, intergrades e instáveis, a partir da construção de um quadro com cinco classes de vulnerabilidade, em cores distintas, sendo elas classificadas de muito baixa até muito alta. Segundo ALVES (2010), estas cores estão relacionadas a valores que foram atribuídos numa escala de 1,0 a 3,0. No planejamento com base na ecologia da paisagem, é dada uma grande ênfase a vegetação, considerada como representativa das inter-relaçóes entre o clima, solos e a influência humana (COSTA, 2009). Faz-se necessário um desenvolvimento da consciência ecológica e o comprometimento da sociedade diante dos alarmantes impactos ambientais causados pela ação antrópica que, na maioria das vezes, não são responsabilizados pelas suas açôes. A abordagem ecodinâmica constituiu um pressuposto teórico e metodológico excelente, pois abrangeu todos os elementos responsáveis pelas alteraçóes espaciais analisadas na pesquisa.
\end{abstract}

\footnotetext{
${ }^{1}$ Doutorando em Geografia. Prof. do Colégio de Aplicaçâo, Universidade Federal de Sergipe, Campus São Cristóvão, Sergipe, Brasil; jailton@ufs.br

${ }^{2}$ Doutoranda em Geografia, UFS, Sergipe, Brasil; aneziamaria.barbosa@gmail.com

${ }^{3}$ Pós-Doutora em Geografia Física (Biogeografia). Profa Associada do DGE e Núcleo de Pós-Graduação em Geografia, UFS, Sergipe, Brasil. Bolsista de Produtividade em Pesquisa do CNPq; rome@ufs.br
} 
Palavras-chave - Análise Ecodinâmica; Barra dos Coqueiros; Pirambu; Sergipe, Brasil

Abstract - The various forms of performance of the components of the biosphere in each space cause very different consequences. The dynamics of the environment is of utmost importance for the conservation and development of various ecological resources existing in the earth's surface. Thus, drawing a parallel with the establishment of landscape units, there is constant changes in the component parts of these ecosystems. The goal of this work was to analyze how the dynamics of ecotopes contributes to the formation and environmental restructuring of the north coast of the state of Sergipe. To this end, the methodological approach used was based on the principles of ecodynamics proposed by TRICART (1977), by evaluating morphodynamic processes found in the area, which characterize the stable, intergrades and unstable environments, from the construction of a frame with five classes vulnerability in different colors, which were classified as very low to very high. According to ALVES (2010), these colors are related to values ranging from 1.0 to 3.0. In planning based on landscape ecology, a great emphasis is given to vegetation, considered as representative of the interrelationships between climate, soils and human influence (COSTA, 2009). It is necessary to develop an ecological awareness and involvement of society in the face of alarming environmental impacts caused by human action which, in most cases, are not accountable for their actions. The approach ecodynamics was an excellent theoretical and methodological assumption, since it covered all the elements responsible for spatial changes analyzed in this investigation.

Keywords - Analysis ecodynamic; Barra dos Coqueiros; Pirambu, Sergipe, Brazil.

\section{1 - Introdução}

Hodiernamente, os estudos voltados para a análise do espaço apresentam-se como referências para compreensão das diversas dinâmicas naturais e sociais que atuam de forma direta ou indiretamente na constituição do meio geográfico.

Deste modo, a análise das dinâmicas naturais tem como contra partida, avaliar os impactos provocados ao longo dos anos, desencadeados pelas modificaçóes nos ecossistemas, constituindo as variadas paisagens do planeta, cujo objetivo é o ordenamento territorial.

Assim, considerar as configuraçôes espaciais existentes nas áreas litorâneas, requer compreender as inúmeras feiçôes das unidades de paisagens que constituem estes ambientes. A intensa complexidade organizacional dos mesmos recebe, a cada dia, grande pressão dos agentes externos, contribuindo, de forma decisiva, na reorganização paisagística destes espaços e servindo, cada vez mais, como fontes de diversos estudos científicos, que tem no litoral seu objeto de investigação.

As formas de relevo são fortemente influenciadas pela ação marinha, associada a outros fatores como a natureza das rochas e a ação climática, e os solos são resultantes da interação de fatores como o clima, cobertura vegetal e hidrografia, que refletem nas rochas as condiçóes ambientais de uma regiáo.

Nesse sentido, o presente artigo teve como objetivo analisar como a dinâmica dos ecótopos contribui para a formação e reestruturação ambiental do litoral norte do estado de Sergipe. Com base neste objetivo, traçou-se uma discussão sobre os fatores e processos 
que dinamizam esta paisagem de maneira intensamente rápida, e que serve de suporte para discutir os mecanismos naturais e antrópicos existentes in lócus.

\section{2 - Localizaçáo da área de estudo}

O Estado de Sergipe, localizado na posição oriental da região Nordeste entre 09031'33” e 11'33'52" de latitude Sul, é controlado durante o ano pelo anticlone semifixo do Atlântico Sul, que dá origem às massas de ar Tropical Atlântica (mTa) e Equatorial Atlântica (mEa). A primeira, proveniente da regiáo oriental do anticlone, atinge o Nordeste brasileiro, provocando os alísios de SE. A segunda, oriunda da parte setentrional do anticiclone, atinge o litoral sergipano, originando os ventos de NE, chamados alísios de retorno. Apesar de possuírem calor e muita umidade nos seus níveis inferiores, a existência, nos níveis superiores, de uma inversão térmica (efeito de subsidência anticiclônica) não permite, em condiçôes normais, instabilidade provocadora de chuvas, assegurando, desta forma, bom tempo e reduzindo as precipitaçóes. Essa estabilidade das massas de ar, herdadas em sua regiāo de origem, cessa praticamente com a atuaçáo dos sistemas frontológicos que se individualizam na Frente Polar Atlântica (FPA) e nas correntes Perturbadas do Leste (Ondas de Leste), que são decisivas na manutenção de um regime pluviométrico caracterizado por chuvas mais abundantes no período outono/inverno.

A área de estudo está localizada na unidade geotectônica Bacia Sedimentar de Sergipe/Alagoas, que apresenta um arranjo estrutural decorrente de falhamentos normais ocorridos durante o Cretáceo Inferior, quando se desenvolveu extenso sistema de grabens (fase rift) que precedeu a abertura do oceano Atlântico, com a separação das placas Sul-Americana e Africana.

Os sedimentos quaternários da região costeira testemunham a história geológica recente da área, onde está evidenciado o último grande episódio trans-regressivo, denominado por BITTENCOURT et al. (1983) Última Transgressão, que ocorreu no Holoceno.

A estrutura geológica compóe-se de sedimentos costeiros aluviais e de praia, que são formaçôes recentes (holocênica), onde se destacam os depósitos fluviais de texturas argilosas e siltosas com deposiçóes orgânicas e de conchas.

Os municípios, pertencentes ao recorte espacial desse estudo, fazem parte do Litoral Norte do Estado de Sergipe, constituindo assim quatro municípios. São eles: Barra dos Coqueiros, Pirambu, Pacatuba e Brejo Grande (Fig. 1).

A escolha de ambos os municípios justifica-se segundo alguns parâmetros, como: variedade de unidades de paisagem e fitofisionomias, hotspots (área de alta diversidade biológica e sob alta pressão antrópica) e diversas intervenções do Estado. 


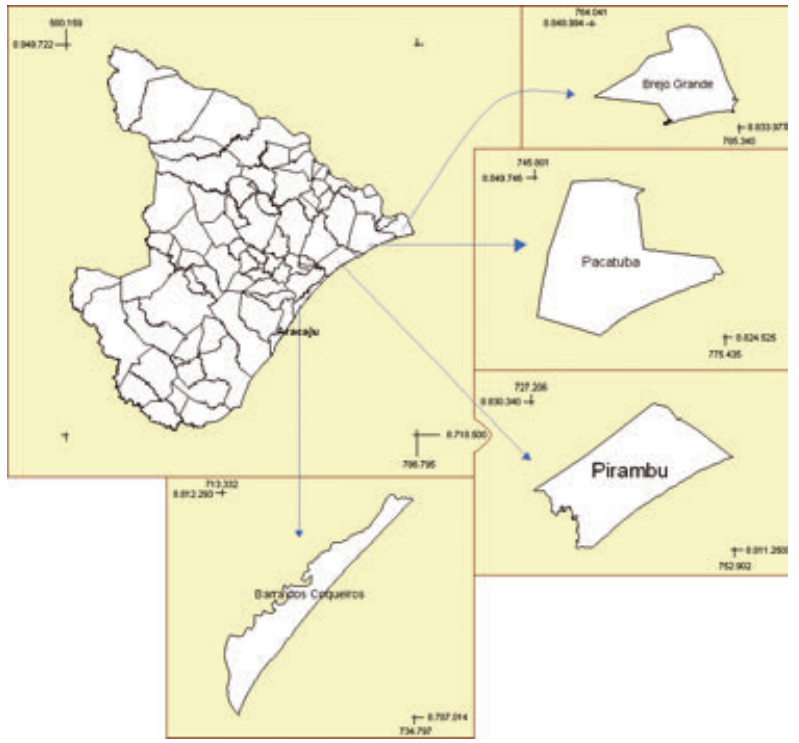

Fig. 1 - Recorte espacial da pesquisa.

De acordo com a tabela 1 abaixo, o estado de Sergipe possui uma população de 2.068.017 ${ }^{4}$ habitantes (IBGE, 2010), dos quais 54.224 habitam a área de estudo, ou seja, $4 \%$ da populaçáo total do Estado. A área total do litoral norte é de $823 \mathrm{~km}^{2}$, o que representa 2,6\% da área total do estado.

Conforme especificado na Tabela 1 , a concentração de um valor relativo da população sergipana, neste espaço, tem contribuído de maneira muito intensa para o processo de planejamento territorial destas áreas, e em especial, na faixa litorânea dos respectivos municípios analisados.

Tabela 1 - Dados gerais de Sergipe, do litoral Norte e dos municípios integrantes.

\begin{tabular}{|c|c|c|c|}
\hline & População Total & Área $(\mathrm{km} 2)$ & Localização Geográfica \\
\hline Sergipe & 2.068 .017 & 22.050 & - \\
\hline Litoral Norte & 54.224 & 823 & - \\
\hline Barra dos Coqueiros & 24.976 & 91 & $10^{\circ} 54 ’ 32^{\prime \prime}$ S e $37^{\circ} 02^{\prime} 19^{\prime \prime} \mathrm{W}$ \\
\hline Brejo Grande & 7.742 & 150 & $10^{\circ} 25^{\prime} 46^{\prime \prime} \mathrm{S}$ e $36^{\circ} 27^{\prime} 58^{\prime \prime} \mathrm{W}$ \\
\hline Pacatuba & 13.137 & 364 & $10^{\circ} 27^{\prime} 10^{\prime \prime}$ S e $36^{\circ} 39^{\prime} 03^{\prime \prime} \mathrm{W}$ \\
\hline Pirambu & 8.369 & 218 & $10^{\circ} 44^{\prime} 16^{\prime \prime} \mathrm{S}$ e $36^{\circ} 51^{\prime} 21^{\prime \prime} \mathrm{W}$ \\
\hline
\end{tabular}

Fonte: IBGE, 2010.

${ }^{4}$ IBGE - Contagem da população (2010). 
Percebe-se que, nas últimas décadas do século XX, a mudança dos meios de produção econômica desenvolvida, sobretudo, nas zonas costeiras da região Nordeste em função da implantação de várias políticas públicas, proporcionou a expansão da atividade como a do turismo, e vem gerando diversos conflitos socioambientais na zona litorânea brasileira.

A área deste estudo se insere no contexto geológico da Bacia Sedimentar Sergipe-Alagoas, estando representada estratigraficamente por rochas do Grupo Sergipe, Grupo Barreiras e sedimentos de praia e aluvióes.

O quadro mais grave registrado na Zona Costeira, particularmente na faixa praial, se observa no município de Brejo Grande, na foz do rio São Francisco, devido a alteraçôes na dinâmica dos processos oceanográficos e fluviais, influenciadas pela instalação das barragens no curso deste rio, tendo como conseqüência a destruição do povoado do Cabeço (observado em campo durante o trabalho técnico) e da área da comunidade da Barra da Costinha.

Nos demais municípios, a ocupação da Zona Costeira é bastante diversificada, sendo verificados loteamentos de segunda residência e acréscimo da rede hoteleira, principalmente em Barra dos Coqueiros (Resort Star Fish) e Pirambu, tendo como causa a proximidade com a capital do Estado de Sergipe. Já nos municípios de Pacatuba e Brejo Grande há uma ampliação significativa da carcinicultura, devido à presença do complexo estuarino lagunar do rio São Francisco.

O litoral sergipano é influenciado diretamente pelas correntes perturbadas que interferem principalmente na pluviosidade, determinando uma concentração das chuvas no outono-inverno, caracterizando-o como o período mais chuvoso (FONTES, 1984).

Para a mesma autora, a porção norte está inserida num ambiente climático que varia de úmido a subúmido, pois sua disposição no segmento litorâneo do estado de Sergipe, sudoeste-nordeste, contribui para uma distribuição diferenciada das chuvas, evidenciando-se a ocorrência de períodos de estiagens que variam de três a cinco meses, a partir de Barra dos Coqueiros em direção a Brejo Grande. Além disso, observa-se também certa variabilidade na distribuição das chuvas do litoral para o interior. Portanto, é este atributo climático o mais importante na definição da tipologia do clima.

O litoral norte de Sergipe está sendo alvo de implementação de planos de construção de infraestruturas com intervençóes em seu espaço litorâneo, a partir da construção da Ponte Construtor João Alves Filho (ligando o município de Barra dos Coqueiros à capital do estado), do Pólo Cloroquímico e Terminal Portuário Marítimo (Barra dos Coqueiros) e instalaçóes da Petrobrás em Pirambu, o que resulta numa maior dinâmica populacional e em vários conflitos de uso e ocupaçáo do solo.

A implantação dessas obras reflete no contexto da economia sergipana e alteram a dinâmica espacial do lugar, sendo resultado de políticas públicas. Algumas destas obras foram responsáveis pela inserção do município de Barra dos Coqueiros no processo de formação da região metropolitana de Aracaju.

\section{3 - A ecodinâmica como metodologia de estudo para análise do espaço geográfico}

Em se tratando de um método direcionado à análise ambiental, o presente estudo traduz-se, enquanto proposta essencial para a formulação de critérios de ordenamento territorial e gestão dos sistemas ambientais analisados, numa perspectiva em que haja 
não só o entendimento dos aspectos políticos e jurídico-institucionais previstos na legislação em vigor (que regem o planejamento público regional), como também a compreensão do problema por parte tanto da comunidade científica como principalmente da população em geral visando, assim, melhor controle ambiental associado à conservação e recuperação dessas áreas já degradadas, com intuito de preservar a riqueza da paisagem.

O método hipotético-dedutivo diferencia as ciências naturais nos estudos geográficos, caracterizando o real através de hipóteses e deduçôes (SPOSITO, 2004). De acordo com VALE (2008), para a Geografia (uma ciência humana que lida com as interfaces das ciências naturais e sociais e, muitas vezes, até com as ciências exatas, sobretudo quando lança mão da Estatística como ferramenta de trabalho), a abordagem sistêmica constitui um pressuposto teórico e metodológico excelente, pois abrange todos os elementos responsáveis pelas alteraçôes espaciais que os geógrafos estão aptos a analisar.

Para complementação das informaçóes levantadas em campo, e visando dar maior consistência a análise, foi realizada coletas de dados preliminares analógicos e digitais, em fontes diversas, disponibilizadas em órgãos da administração pública direta e indireta, como artigos científicos, livros, teses de doutorado, dissertaçóes de mestrado e monografias do curso de Bacharelado em Geografia da Universidade Federal de Sergipe.

A caracterização das unidades de paisagem com destaque para as fitofisionomias foi realizada com o uso da máquina fotográfica e do sistema de posicionamento global GPS, em intervalos abertos, abrangendo todas as unidades.

Foi utilizado como base cartográfica na elaboração das cartas o Atlas Digital Sobre Recursos Hídricos do Estado de Sergipe/SEPLAN/SRH-2004. O software utilizado na confecção dos mapas e das cartas foi o Sistema de Processamento de Informaçóes Georreferenciadas na versão 5.0 (SPRING 5.0).

Fez-se uso, também, de fotografias próprias adquiridas durante os trabalhos de campo.

Quanto às análises do espaço, segundo a metodologia CREPANI (1996, apud ALVES, 2010), os estudos que se referem a avaliar as diversas formas de vulnerabilidades ambientais que constituem a paisagem, tornam-se necessários para que haja o envolvimento de vários condicionantes geoambientais, constituintes nas unidades de paisagens.

De acordo com a Metodologia de CREPANI (1996), trabalha-se com o limite mínimo 1,0 e máximo 3,0 com intervalos de 0,1 décimo, ou seja, 21 valores possíveis. É uma metodologia para facilitar a divisão de qualquer região em classes com maior ou menor vulnerabilidade aos processos de perda de solo. Para avaliar cada unidade de paisagem e chegar a uma caracterização sobre a sua vulnerabilidade, é realizada uma média aritmética entre os valores já definidos de cada um dos temas, sedo a vulnerabilidade o resultado da soma de valores da Geologia, Geomorfologia, Pedologia, Vegetação e uso do solo, sempre dividido por cinco.

Para facilitar o estudo e o entendimento, adotou-se trabalhar com cinco cores obtidas a partir da combinação das três cores aditivas primárias (azul, verde e vermelho) de modo que se associasse a cada classe de vulnerabilidade sempre a mesma cor, obedecendo ao critério de que ao valor de maior estabilidade $(1,0)$ se associa a cor azul, ao valor de estabilidade intermediária $(2,0)$ se associa a cor verde e ao valor de maior vulnerabilidade $(3,0)$ a cor vermelha.

Aos valores situados entre 1,0 e 1,7 na escala de vulnerabilidade associam-se cores resultantes da combinação entre o azul e o verde (pedogênese), crescendo a participação do segundo à medida que se aproxima de 2,0 , enquanto que aos valores situados 
entre 1,8 e 2,2 apresenta-se somente a cor verde (integrade), e entre o intervalo de 2,3 e 3,0 visualiza-se as cores amarelo e vermelho (morfogênese), crescendo a participação do segundo a medida em que o valor da vulnerabilidade se aproxima de 3,0, ou seja, do limite extremo.

Dessa forma, para a elaboração do quadro síntese, o qual apresenta a avaliação de uso e ocupação das paisagens constituintes no complexo, que formam o litoral norte do Estado de Sergipe, principalmente a área de estudo formada pelos municípios de Barra dos Coqueiros e Pirambu, elaborou-se um quadro com 5 (cinco) classes de vulnerabilidade, sendo elas classificadas entre muito baixa e muito alta. Estas serviram de suporte para analisar as categorias ecodinâmicas, as quais encontram-se classificadas nos seguintes parâmetros - estáveis, pouco estáveis, intergrade, pouco instável e instável. Para este esboço metodológico, cada classe está relacionada a uma escala de cores que representam os intervalos entre cada uma delas (Quadro 1).

Quadro 1: Valores para a avaliação Ecodinâmica das Unidades de Paisagens dos municípios de Barra dos Coqueiros e Pirambu - Sergipe (Fonte: Adaptado de CREPANI et al., 1996, apud ALVES, 2010).

\begin{tabular}{|c|c|c|c|c|}
\hline Nível & $\begin{array}{c}\text { Escala de } \\
\text { cores }\end{array}$ & $\begin{array}{c}\text { Classe de } \\
\text { Vulnerabilidade }\end{array}$ & $\begin{array}{l}\text { Categorias } \\
\text { Ecodinâmicas }\end{array}$ & Relação Morfogênese e Pedogênese \\
\hline $\begin{array}{c}1 \\
1,0-1,3\end{array}$ & & Muito Baixa & Estável & Prevalece a pedogênese \\
\hline $\begin{array}{c}2 \\
1,4-1,7\end{array}$ & & Baixa & Pouco Estável & Tendência para prevalecer a pedogênese \\
\hline $\begin{array}{c}3 \\
1,8-2,2\end{array}$ & & Média & Intergrade & Equilíbrio entre ambos \\
\hline $\begin{array}{c}4 \\
2,3-2,6\end{array}$ & & Alta & Pouco Instável & Tendência para prevalecer a morfogênese \\
\hline $\begin{array}{c}5 \\
2,7-3,0\end{array}$ & & Muito Alta & Instável & Prevalece a morfogênese \\
\hline
\end{tabular}

\section{4 - Resultados}

A atual infraestrutura socioambiental das cidades de Barra dos Coqueiros e Pirambu é precária, beirando situaçóes de risco, porque se sabe da ausência do saneamento ambiental, ou seja, da falta de sistema de tratamento de esgoto e de condiçóes adequadas para disposição dos resíduos sólidos. Também, um dos problemas mais sérios enfrentado pela população de Barra dos Coqueiros é o abastecimento de água potável, pois aquela que serve a população é proveniente de poços artesianos oriundos do lençol freático. Como a recarga do aqüífero não satisfaz a crescente demanda, espera-se uma invasão da cunha salina, ameaçando as condiçóes de potabilidade da água, cuja salinidade vem aumentando ao longo do tempo.

Percebe-se que grande parte do recorte espacial deste estudo é ocupado por vegetação secundária (plantação de Cocos nucifera, Hancornia speciosa e algumas culturas de subsistência) com pequenas áreas de mangues, campos de várzeas e de restingas.

A tabela 2 a seguir, traz a síntese da análise ecodinâmica da área de estudo. 


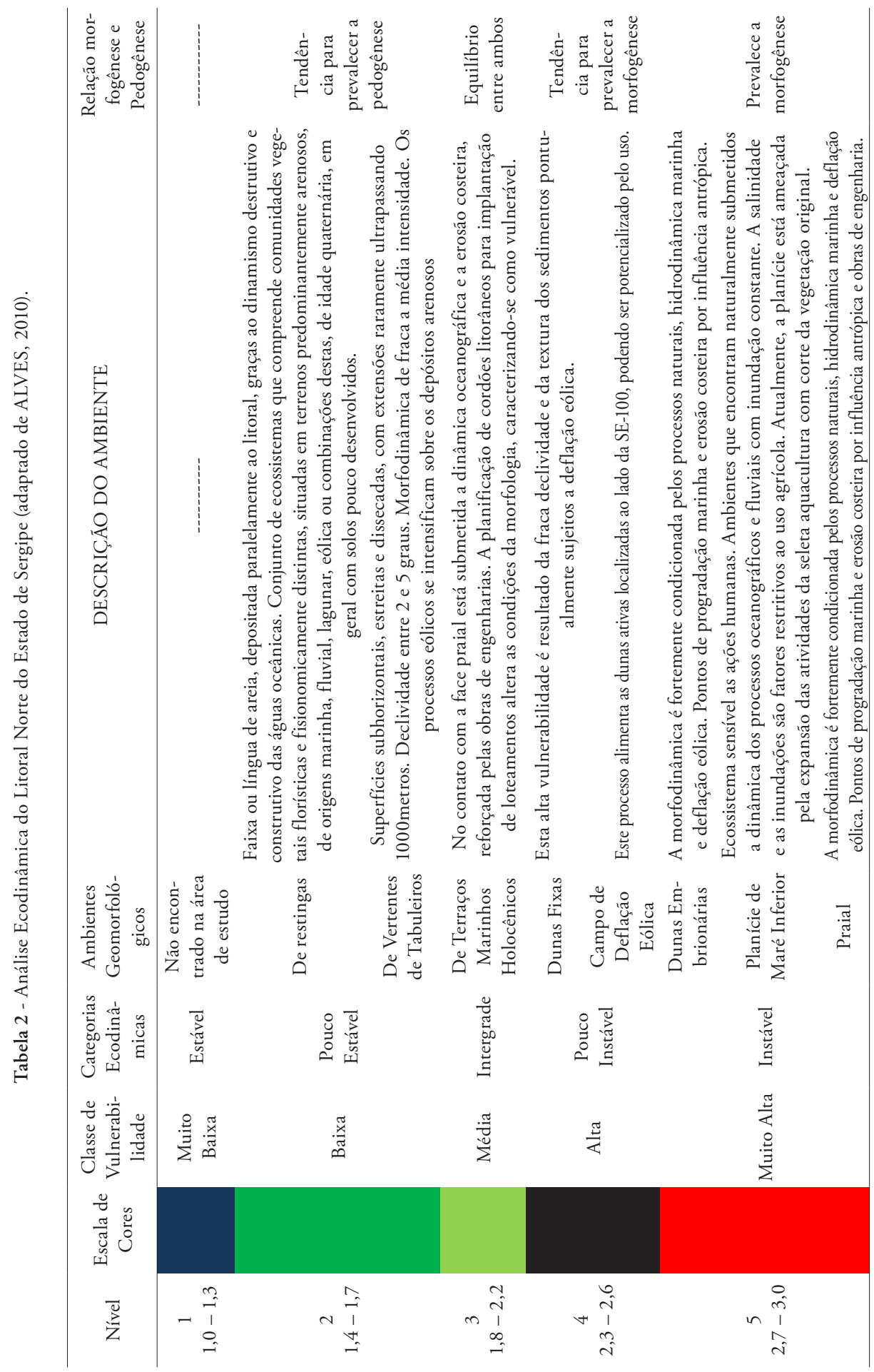


A vegetação pode ter seu desenvolvimento prejudicado nas áreas de passagem dos veículos, podendo haver a remobilização de dunas que antes estavam em processo de fixação. Portanto, é importante que as trilhas para veículos sobre as dunas sejam reduzidas ou ainda deslocadas para áreas onde seus impactos sejam menores para a sucessão da vegetação. A participação da comunidade nas decisóes relativas a atividades turísticas se faz importante, uma vez que estáo perdendo seu espaço territorial, ambiental e cultural.

A presença do gado afeta a vegetação costeira de duas maneiras: pelo pisoteio (formação de trilhas) e pela herbivoria. Ambas, pisoteio e herbivoria, alteram a composição e abundância de espécies da cobertura vegetal, provocando danos à fauna e flora locais.

Com base nos trabalhos de campo verificou-se a erosão marinha em diversos trechos da área estudada. Observou-se na área duas ocorrências de dunas com idades geológicas diferentes que integram o contexto geomorfológico do litoral de Sergipe; as dunas mais antigas são mais interiorizadas (atingindo cerca de $30 \mathrm{~m}$ de altura); as dunas mais recentes são de posicionamento adjacente às extensóes de praia; ambas geraçóes de duna são barcanas. É notório o potencial eólico, principalmente no município de Pirambu, onde há o campo dunar mais expressivo e a captação de energia eólica para bombear água de poços.

A paisagem da área de estudo é considerada peculiar devido à sua formação recente. Geologicamente, grande parte da regiâo se apresenta instável e com alta vulnerabilidade com processos de perda de solo devido a fatores naturais como declividade, precipitação, ausência de cobertura vegetal, muitas vezes, intensificados pela ação antrópica como a ocupação desordenada, queima da vegetação, abertura de caminhos na praia (recreação, pavimentação e obras), entre outros.

\section{5 - Consideraçóes finais}

No planejamento com base na ecologia da paisagem, é dada uma grande ênfase a vegetação, considerada como representativa das inter-relaçóes entre o clima, solos e a influência humana. Informaçôes sobre a vegetação são consideradas essenciais no desenvolvimento de um sistema de informaçôes, devido a sua influência sobre o manejo dos recursos, e a interaçáo com os outros atributos da paisagem, uma vez que pode ser considerada como um indicador das características dos mesmos.

Faz-se necessário um desenvolvimento da consciência ecológica e o comprometimento da sociedade diante dos alarmantes impactos ambientais causados pela açáo antrópica, que na maioria das vezes não são responsabilizados pelas suas açóes.

A metodologia de CREPANI constitui uma ferramenta excelente, pois abrange todos os elementos responsáveis pelas alteraçóes espaciais analisadas na pesquisa, sendo sua aplicação importante para o planejamento, pois permite o monitoramento constante da área.

\section{Referências Bibliográficas}

ALVES, N. M. de S. (2010) - Análise geoambiental e socioeconômica dos municípios costeiros do litoral norte do estado de Sergipe - diagnóstico como subsídio ao ordenamento e gestão do território. Tese de Doutorado, Núcleo de Pós-Graduação em Geografia. Universidade Federal de Sergipe - UFS, São Cristovão, 324 p. 
BitTEnCOURT, A. C.; MARTin, L; DOMINGUEZ, J. M. L. \& FERREIRA, Y. A. (1983) - Evolução Paleogeográfica Quaternária da Costa Sul do Estado de Alagoas. Revista Brasileira de Geociências, $13(2), 93-97$.

COSTA, J. de J. (2009) - Biorecuperação de Dunas Costeiras do Litoral Norte de Sergipe. Dissertação de Mestrado, Núcleo de Pós-Graduação em Geografia. Universidade Federal de Sergipe - UFS, São Cristovão, $175 \mathrm{p}$.

CREPANI, E.; MEDEIROS, J. S.; AZEVEDO, L.G.; HERNANDEZ FILHO, P.; FLORENZANO, T.G. \& DUARTE, V. (1996) - Curso de sensoriamento remoto aplicado ao zoneamento ecológico econômico [CD-ROM]. In: Simpósio Brasileiro de Sensoriamento Remoto Curso de sensoriamento remoto aplicados ao zoneamento ecológico-econômico [CD-ROM]. In: Simpósio Brasileiro de Sensoriamento Remoto, 8, Salvador, Anais. São Paulo.

FONTES, A. L. (1984) - O Cenozóico na bacia inferior do rio Japaratuba (SE). In: Congresso Brasileiro de Geologia, 33, Anais. Belém.

IBGE (2010) - Censo demográfico. Rio de Janeiro: IBGE. Disponível em: <http://sidra.ibge.gov.br/cd/cd2010rpv.asp?o=4\&i=P>. Acesso em: Jan. 2012.

SPOSITO, E. S. (2004) - Geografia e Filosofia: contribuição para o ensino do pensamento Geográfico. São Paulo: UNESP.

TRICART, J. (1977) - Ecodinâmica. Rio de Janeiro: IBGE/SUPREN, (Recursos Naturais e Meio Ambiente), 91 p.

VALE, C. C. do (2008) - Por uma Metodologia para o Estudo das Áreas de Manguezais: uma visão sistêmica. In: NUNES, J. O. R. \& ROCHA, P. C. (Orgs.). Geomorfologia: aplicação e metodologias. São Paulo: Expressão Popular, Unesp. 192 p. 